\title{
The effects of corporate social performance on the cost of corporate debt and credit ratings
}

Article

Accepted Version

Oikonomou, I., Brooks, C. and Pavelin, S. (2014) The effects of corporate social performance on the cost of corporate debt and credit ratings. Financial Review, 49 (1). pp. 49-75. ISSN 1540-6288 doi: https://doi.org/10.1111/fire.12025 Available at https://centaur.reading.ac.uk/35763/

It is advisable to refer to the publisher's version if you intend to cite from the work. See Guidance on citing.

Published version at: http://onlinelibrary.wiley.com/doi/10.1111/fire.12025/abstract

To link to this article DOI: http://dx.doi.org/10.1111/fire.12025

Publisher: Wiley

All outputs in CentAUR are protected by Intellectual Property Rights law, including copyright law. Copyright and IPR is retained by the creators or other copyright holders. Terms and conditions for use of this material are defined in the End User Agreement.

www.reading.ac.uk/centaur 
Central Archive at the University of Reading

Reading's research outputs online 


\title{
The Effects of Corporate Social Performance on the Cost of
}

\section{Corporate Debt and Credit Ratings}

\author{
Ioannis Oikonomou, ICMA Centre, University of Reading, UK \\ Chris Brooks*, ICMA Centre, University of Reading, UK \\ Stephen Pavelin, School of Management, University of Bath, UK
}

JEL Classification: C33, G32, M14

Keywords: corporate social responsibility, CSP, socially responsible investing, credit ratings, cost of debt, credit spreads, corporate bonds

\footnotetext{
* Corresponding author: Chris Brooks, ICMA Centre, Henley Business School, University of Reading, Whiteknights, Reading RG6 6BA, UK; Phone: +44 118378 8239; Fax: +44 118931 4741; E-mail: C.Brooks@,reading.ac.uk
}

Acknowledgements: We are grateful to the Editor, Robert Van Ness, and to two anonymous referees for useful comments that considerably improved the paper. We also thank Davide Avino for helping us with the overview of the literature of corporate bond spread determinants. 


\title{
The Effects of Corporate Social Performance on the Cost of
}

\section{Corporate Debt and Credit Ratings}

\begin{abstract}
This study investigates the differential impact that various dimensions of corporate social performance have on the pricing of corporate debt as well as the assessment of the credit quality of specific bond issues. The empirical analysis, based on an extensive longitudinal data set, suggests that overall, good performance is rewarded and corporate social transgressions are penalized through lower and higher corporate bond yield spreads respectively. Similar conclusions can be drawn when focusing on either the bond rating assigned to a specific debt issue or the probability of it being considered to be an asset of speculative grade.
\end{abstract}




\section{Introduction}

The notions of corporate social responsibility and corporate social performance ${ }^{1}$ (CSP) demonstrative of the degree to which firms incorporate social and environmental concerns in their operations - have been of significant interest to both the academic and business world for the last four decades. Nevertheless, it is a common perception that issues relevant to corporate social performance have become more prominent in recent years (Starks, 2009).

Faced with these new pressures, firms have to reorient their perspective and business operation and it appears that they are aware of this. This is supported by the UN Global Compact-Accenture CEO Study, based on a 2010 survey of more than 750 CEOs. Overall, 93\% of them see sustainability as a factor that can materially influence their firm's future success. Perhaps the most characteristic figures showing the increasing public awareness of CSP issues come from the socially responsible investing (SRI) movement. According to the US Social Investment Forum, in 1995 there were just 55 SRI funds with $\$ 12$ billion assets under their management whereas in 2010 there were 250 socially screened mutual funds in the US with total assets of $\$ 316.1$ billion. These figures translate to a $455 \%$ increase in the number of SRI funds and a staggering $2,634 \%$ increase in the value of the assets in these funds.

Given these evolutions and trends, it is perhaps unsurprising that a wide-ranging academic literature has been developed, with studies going as far as exploring the connections of CSP with political beliefs (Rubin, 2008). The most substantial part of this literature concentrates on the nature, magnitude, and significance of the connection of CSP with corporate financial performance (CFP). Although numerous papers have been written and published in this area, as evidenced by the existing comprehensive reviews (Margolis and Walsh, 2003; Renneboog, Ter Horst, and Zhang, 2008a), no consensus has been reached with regard to the empirical relationship

\footnotetext{
${ }^{1}$ Although there are some distinguishing differences between the terms, they tend to be used interchangeably in the bulk of the related literature (Barnett, 2007); we will exclusively employ the term CSP in this study.
} 
between CSP and CFP either at the firm level (Brammer, Brooks, and Pavelin, 2006; Edmans, 2011) or at the portfolio level of analysis (Bauer, Koedijk, and Otten, 2005; Galema, Plantinga, and Scholtens, 2008; Renneboog, Ter Horst, and Zhang, 2008b).

The majority of studies investigating the CSP-CFP link look at CSP resources as being potentially value creating (or value destroying) by attempting to connect measures of corporate social performance with some risk-adjusted measure of financial performance. Although it is intuitive to look at corporate social responsibility as value creation, this rationale fails to recognise CSP as an aspect of risk management. It can be supported that a company that is consistently socially or environmentally responsible (or at least less irresponsible) should enjoy financial benefits in the form of fewer downward adjustments and less volatility in its share price compared with less socially responsible, or more irresponsible, firms.

The validity of the conjecture that superior CSP can lead to a reduction of financial risk could be tested in the context of equity or debt markets alike. With the exception of very few, recently published studies, the entire literature focuses on an examination of the impact of CSP on the systematic firm risk (Aupperle and Van Pham, 1989; Oikonomou, Brooks, and Pavelin, 2012) or idiosyncratic risk (Lee and Faff, 2009; Luo and Bhattacharya, 2009) of publicly traded firm shares. However, the bond market could prove more suitable for conducting such an investigation. The U.S. corporate debt market is a very large (approximately $\$ 7.5$ trillion outstanding market debt during the fourth quarter of 2010 ), very active (with an average daily trading volume between $\$ 14.1$ and $\$ 19.7$ billion for the period January to December 2010) and dynamic market (with new bond issuance reaching $\$ 1,063$ billion during 2010 versus only $\$ 262$ billion total equity issued in the same year). ${ }^{2}$ Furthermore, because, in general, companies need to refinance themselves in the debt market more frequently than in the equity market (due to the limited maturity of short- and

\footnotetext{
2 Data come from the Securities Industry and Financial Markets Association's (SIFMA) publicly available records and Bloomberg.
} 
medium-term bonds), the former appears to be more suitable for socially aware groups to implicitly exercise stakeholder activism and the company will have to meet their demands or suffer higher costs of debt.

The credit market is also more of an institutional investor's arena in comparison with the equity market. Approximately $86 \%$ of U.S. corporate bonds are institutionally owned while the equivalent percentage for U.S. equity is about $64 \% .{ }^{3}$ Greater institutional participation is a desirable property for CSP_CFP research for two reasons. Firstly, institutional investors are generally believed to be better informed than private investors and because of this it is more likely that they will take under consideration a complicated issue such as CSP when allocating the wealth they manage. Secondly, high institutional participation decreases free float bonds (i.e., increases the concentration of bonds in the hands of particular investors), thus making it easier for bondholders to "discipline" firm management when they need to (Menz, 2010) by simply selling (or even short selling) the respective corporate bonds, hence increasing the cost of debt for transgressing firms.

That firms with better corporate social performance have lower stock return volatilities is indicative of a correspondingly lower volatility in the firm's underlying asset values and this would suggest a lower default risk. A lower susceptibility to the undesirable consequences of poor social performance outlined above is also suggestive of lower expected losses from default, which would in turn suggest a link with bond ratings through this mechanism. If this is indeed the case, and if bond ratings fully reflect all available and relevant information pertaining to default risks, then when we incorporate bond ratings into a model for yield spreads, there should be no further role for CSP (which would be subsumed into the ratings themselves). However, the intangible nature of the wealth-protective effects of good CSP (and the reverse for poor CSP) could be appreciated

\footnotetext{
${ }^{3}$ Data come from the 2010 national data book of the U.S. Census Bureau. The percentages refer to domestic investors only. There is a number of foreign investors in both markets but the database does not make any distinction between households and institutions in their case so actual percentages could be modestly different.
} 
by the markets and therefore affect spreads but may not be fully captured in the models used by ratings agencies. ${ }^{4}$

This is the first piece of research that looks at both the differential impact of disaggregated measures of corporate social performance as well as the combined effect of various CSP dimensions on fixed-income instruments. It also makes use of an extensive longitudinal data set to test these effects on both the corporate cost of debt and the credit ratings assigned to the corporate bonds and control for a wide array of financial variables (relevant to the issuing firm and the bond itself). In addition, emphasis is placed on revealing some of the particularities in the link between CSP and the cost of debt concerning the role of the investment horizon and the operational nature of the issuing firm.

\section{Related literature and development of hypotheses}

\subsection{Existing empirical work on the relation between CSP and credit risk}

One of the very few related CSP-CFP studies that is conducted within the context of corporate debt is that of Menz (2010), who looks at the European corporate bond market using the Corporate Sustainability Assessment of the Sustainable Asset Management Research (SAM) as his source for CSP data and finds that, ceteris paribus, the risk premium for socially responsible firm bonds does not significantly differ from that of less responsible corporations.

Bauer and Hann (2010) focus solely on the environmental dimension of CSP but use information from a larger, cross-industrial sample of U.S. public corporations. Treating environmental strengths and concerns as different constructs, they show that the former are associated with a lower cost of debt and the latter are linked with both a higher corporate yield spread and lower credit ratings. Frooman, Zietsma, and McKnight (2008) reach similar conclusions when using a multidimensional measure of CSP for a single year of data (2006) and show that there

\footnotetext{
${ }^{4}$ The authors are grateful to an anonymous referee for suggesting this conceptual avenue.
} 
is an inverse relation between default risk (captured by Moody's ratings) and CSP. In addition, there is the study of Goss and Roberts (2011), which is also relevant as it investigates the impact of CSP on debt markets but concentrates on the cost of bank loans rather than bond yields. Their findings are mixed and suggest that banks are indifferent to discretionary CSP investments by highquality borrowers but they impose higher spreads on low-quality borrowers who engage in socially responsible practices.

Indicative of the growing interest in and importance of this particular topic is the work of Ge and Liu (2012). The authors examine the effects of CSP disclosure on the spreads of new corporate bond issues from the U.S. primary bond market. Their results suggest that firms disclosing good corporate social performance are associated with lower bond spreads compared with non-disclosure firms, but there is no significant difference between the bond spreads of firms disclosing poor CSP and those of non-disclosure firms. The work of Ge and Liu (2012) is the most closely related to our own study although the two have significant differences with regard to contribution, sample construction, and research design. First of all, the point of emphasis in the work of Ge and Liu is the differences in the cost of debt between firms that disclose their CSP and firms that do not, whereas this study focuses on the differential financial effect of CSP among firms that are rated on a multitude of issues concerning their social and environmental practices. Secondly, the Ge and Liu study makes use of bonds solely from the primary bond market, which means that $91 \%$ of their sample consists of issues that have a call, put, or convert option embedded. In contrast to this, we make use of data from the primary and secondary bond markets and do not include any bonds with non-standard characteristics in our analysis. We believe that this choice on our part adds clarity and generality to the inferences that can be drawn from our empirical results. Lastly, the operationalization of CSP is quite different in the two papers. Ge and Liu elect to use all the indicators of strengths, concerns, and controversial business issues and amalgamate them in respective general indicators. Our study, on the other hand, draws from 
seminal work in stakeholder theory and focuses on those CSP issues that can be directly connected to key stakeholder groups and are crucial to a firm's viability and financial success.

Our work attempts to considerably move the literature forward by filling a number of gaps left by previous research. It utilizes an extensive cross-industrial longitudinal data set of U.S. bonds for the years between 1991 and 2008, creating a sample consisting of several thousand firm-year observations. The size and heterogeneity of this sample are both desirable and uncommon features in the literature. This paper also permits an investigation of the effect that many different dimensions of CSP have on bond pricing instead of a single one. Furthermore, it goes beyond quantifying the effects of CSP on corporate spreads to searching for a similar link with respect to the bond ratings assigned by professional rating agencies and to uncovering some of the finer points of these associations with regard to the optimal investment horizon and bond characteristics.

\subsection{Conceptual background}

The principal viewpoint that this study takes in the relation between CSP and credit risk/corporate spreads/bond ratings follows the reasoning that has been put forward by stakeholder theorists. Arguably, there are stakeholders who attempt to infer a firm's underlying corporate character and moral coloration according to its CSP record. If this perception of corporate character is deemed to be one of a trustworthy and cooperative partner, then it can result in a significant competitive advantage (Jones, 1995). So, it is supported that a firm that is proactively responsible in its interactions with society and its treatment of the natural environment is more likely to, inter alia, improve customer loyalty, increase employee attraction and retention rates as well as productivity, effectively lobby for government and state tax breaks, and, finally, have a superior access to capital compared with a firm that does not pay attention to its social posture.

Similarly, a firm that is found to behave irresponsibly in a given dimension of its corporate social performance risks a higher probability of a class of negative events occurring such as product 
boycotts, employees going on strike or withholding best efforts, imposition of fines, penalties, government sanctions, punitive damages, and associated litigation costs. Such events could lead to a higher cost of debt for the transgressing corporation. In the most notable relevant historical examples, the effects of corporate social irresponsibility on credit ratings and bond spreads were staggering. For instance, the oil spill incident in the Gulf of Mexico led to the BP bond with about three years to maturity being traded with a spread of about 7.57\% (June 9, 2010), more than 30 basis points above the average spread of "junk bonds" at the time according to the relevant Bank of America Merrill Lynch indexes. A few days later, the rating agency Fitch slashed the firm's rating from AA to BBB. So the firm's reputational damage was quickly transformed to an important liquidity problem, which could have escalated to a significant solvency and viability issue. Finally, as Bauer and Hann (2010) note, significant environmental liabilities can create insurmountable risks for a firm, making it tempting for its management team to consider filing for strategic bankruptcy in an attempt to avoid them. The same rationale can be extended to consumer and employee safety issues or to equal opportunity cases. Given this, the default probability and loss severity of bondholders' investments in firms that tend to expose themselves to these types of risks are higher than those of the respective investments in corporations that proactively shield themselves against such hazards.

There are additional reasons why CSP could have an effect on a firm's credit ratings and cost of debt. According to the seminal work of Jensen and Meckling (1976) concerning managerial behavior and agency costs, there is a significant agency problem affecting both the shareholders and creditors of a firm in that managers can take decisions against the objective of firm value maximization, either because they are acting in self-interest or because they are incompetent. The integration and effective management of a highly complex issue such as CSP in a firm's operations could convince stakeholders of the managerial teams' competence and trustworthiness, thus limiting the potential hazards arising from agency risks and lowering the firm's costs of debt and 
equity. This signalling effect is at the core of the "good management" theory (Waddock and Graves, 1997).

As Ashbaugh-Skaife, Collins, and LaFond (2006) note, there is another type of agency conflict arising between bondholders and shareholders. This has to do with the asymmetric payoffs accruing from a corporate bond. Merton (1973) has shown that these payoffs can be replicated by taking a long position in the firm's assets and a short position in a call option on the same assets (i.e., a strategy equivalent to a synthetic short put on the firm's assets). This means that the potential losses of a bondholder are the entire amount she has invested while the potential gains are capped. That is why it can be argued that it is even more crucially important for bondholders to be able to discern good managers from bad ones when choosing where to allocate their wealth and so the "good management" reasoning may have a greater observable effect in the bond market. So, according to all the arguments presented in the previous discussion, the principal hypotheses being tested in this study are:

Hypothesis 1: Firms with more social and environmental strengths have lower credit spreads (lower cost of debt financing) and higher corporate bond ratings (lower default risk).

Hypothesis 2: Firms with more social and environmental concerns have higher credit spreads (higher cost of debt financing) and lower corporate bond ratings (bigher default risk).

It is also possible that the effect of CSP on credit spreads will differ according to the time horizon of an investment. Prior literature has argued that the financial effects of the various dimensions of corporate social performance are more likely to accrue in the long run through "effective stakeholder management - relations with primary stakeholders to include customers, employees, suppliers, community residents and the environment - (which) constitute intangible, socially complex resources that may enhance firms' ability to outperform competitors" (Hillman and Keim, 2001, p. 127). In addition, Cox, Brammer, and Millington (2004) provide empirical evidence 
showing that long-term institutional investor ${ }^{5}$ holdings in firms are positively related to corporate social performance, thus corroborating similar earlier findings by Graves and Waddock (1994). As noted previously, institutional participation is greater in the bond market than the equity market so the differential effects of the time horizon of investment should be easier to spot in studies focusing on the effect of CSP on bonds rather than stocks. Hence, assuming that a significant proportion of bond investors follow a "buy and hold" strategy:

Hypothesis 3: The effect of corporate social performance on corporate spreads is more pronounced in bonds of longer maturities.

We will now proceed to systematically describe the technical details concerning the analyses conducted to test the above hypotheses.

\section{Research design}

\subsection{Corporate social performance measures}

KLD STATS is our database of choice for social and environmental corporate data. KLD Research and Analytics ${ }^{6}$ is the prominent rating agency responsible for the provision of environmental, social and corporate governance (ESG) information. KLD rates firms on numerous factors that are indicative of different dimensions of CSP (relationship and involvement with local communities, diversity issues, employee programs, environmental matters, product safety and quality, corporate governance, and human rights). The rating is binary (zero when the specific indicator is irrelevant to the firm's posture, one if it is relevant). KLD uses information both internal and external to the firm to make its assessment (from annual reports and newspaper articles to on-site visits) and is consistent in the application of the criteria it uses.

\footnotetext{
${ }^{5}$ Long-term institutional investors include pension funds, life assurance funds, and charitable funds. ${ }^{6}$ Acquired by RiskMetrics Group in 2009 - now part of MSCI.
} 
We focus on those qualitative business issues that can be explicitly connected to particular stakeholder groups that, through their actions, can influence the social posture, profile, and activities of the firms. According to the seminal work of Hillman and Keim (2001) these are: i) community issues, ii) diversity issues, iii) employee relations, iv) environmental issues, and v) product safety and quality. We also follow the findings of Mattingly and Berman (2006) as well as Lankoski (2009) concerning the conceptual and empirical differences between positive and negative corporate social actions and keep the strengths and concerns dimensional components separate (i.e., we do not subtract concerns from strengths but construct separate measures). To create these measures, we simply add the scores of the indicators that comprise each social dimension of positive or negative corporate actions and divide each sum by the number of relevant indicators. In addition, we construct "aggregate strengths" and "aggregate concerns" measures by adding the scores of the relevant individual components across all five CSP dimensions of interest and dividing the sum by five so that the estimated slope coefficients are comparable across different models. The use of aggregate social performance of firms can help us draw higher-level inferences concerning the overall sign and strength of the link between CSP and CFP, which is ultimately what bond investors and firm managers would like to know.

\subsection{Cost of debt and credit quality measures}

We make use of three different key variables that capture aspects of the corporate cost of debt and credit risk to test the relevance of corporate social performance for bond investors: corporate spreads, corporate bond ratings, and a dummy variable equal to one when the bond is speculative grade and zero when it is investment grade. The data for the construction of all of these variables are collected from Thomson Reuters DataStream. By definition, the corporate spread of a given bond at a given point in time is equal to the yield of the bond minus the yield of a sovereign bond that is identical to the corporate bond in every characteristic (maturity, coupon rate, frequency of payments per year) except for credit risk. Since the yield curve cannot be observed from the 
market, it has to be estimated. Given that the focus of this study is on identifying whether CSP is a determinant of credit risk, the smoothness of the curve is a more desirable characteristic compared with the issue-specific fit of the data and parametric approaches seem a reasonable choice for modeling the yield curve. Thus we use the data set of Gürkaynak, Sack, and Wright (2007) who construct daily U.S. Treasury yield curves from 1961 onwards using the extension by Svensson (1994) of the functional form proposed by Nelson and Siegel (1987) in their seminal study.

Based on this data set, we create synthetic Treasuries with identical payments (adjusting for coupon rates and the number of payments per year) and maturities matched to the nearest integer, thus eliminating any distortions arising from differences in duration and convexity between the corporate bond and the original sovereign bond. We can then subtract these yields from the yields of the corresponding corporate bonds to calculate the credit spread. We repeat this process for monthly intervals and average the spreads for a given bond during a given year. We take the logarithm of this mean to adjust for the significant positive skewness in the yield spread distribution and use it as the dependent variable in our models.

The second dependent variable we employ is the bond rating score, which we get by standardizing the Standard \& Poor's (S\&P) bond issue rating classifications (we make use of the S\&P Historical Bond Rating data type from Thomson Reuters DataStream). This ordered ranking scale ranges between one (for the lowest rated bonds) and eight (for the highest rated bonds), and is very similar to the one used by Ashbaugh-Skaife, Collins, and LaFond (2006). Whenever a bond rating changes during the course of a given year, its various rating scores are averaged and rounded to the nearest integer. The third and last dependent variable we use is a dummy variable equal to one when the bond is speculative grade and zero when it is investment grade. Although less informative than either of the previous two variables, this binary measure clearly answers the interesting question of whether lower CSP values are connected with a higher probability of particular corporate bonds being perceived as assets of speculative grade. 


\subsection{Control variables}

A series of additional explanatory variables is included in the models specified based on the existing literature concerning the determinants of credit spreads and corporate bond ratings as well as research examining the effect of corporate governance and CSP facets on credit risk (including, inter alia, Ashbaugh-Skaife, Collins, and LaFond, 2006; Bhojraj and Sengupta, 2003; CollinDufresne, Goldstein, and Martin, 2001; Elton, Gruber, Agrawal, and Mann, 2001; Ziebart and Reiter, 1992). This set of variables can be taxonomized in two broad categories: factors that control for firm characteristics and factors that control for issue characteristics.

\subsubsection{Firm characteristics}

Firm size is used as a control variable because, in general, larger firms tend to face lower business and financial risks and are therefore expected to have bonds with lower credit spreads and higher ratings. The logarithm of the firm's market capitalization is used as a proxy for firm size. Higher leverage (captured by the total debt to common equity ratio) is thought to be associated with higher default risk as firms that accumulate more debt may find it harder to service it at a future date. The same logic applies to the interest coverage ratio (equal to the ratio of the firm's earnings before interest and taxes, EBIT, over its interest expenses), which should be positively linked with ratings and negatively with spreads. Return on assets (ROA) is another accounting-based ratio (equal to EBIT over total assets), which demonstrates the efficiency with which the firm uses its resources and assets and its ability to produce significant profit to cover its debt obligations. The market-tobook ratio is also employed as its reciprocal is thought to be associated with the distress factor of Chan and Chen (1991). Firm liquidity (proxied by the current ratio, which is equal to a firm's book value of current assets over the book value of its current liabilities) demonstrates the ability of the firm to remain solvent in the short run. In addition, we follow the findings of McWilliams and Siegel (2000) and use research and development (R\&D) intensity (captured by the R\&D expenditure over total sales ratio for a given firm in a given year), which has been found to moderate the relation between CSP and CFP in general and can be hypothesized to play a similar 
role in the link between CSP and credit risk in particular given the riskiness that comes with investing in $\mathrm{R} \& \mathrm{D}$ to produce innovative products and services. Lastly, we use the Industry Classification Benchmark (ICB) taxonomy at its second level of analysis, which categorizes companies according to the supersector in which they operate, and we construct a series of dummy variables to account for the heterogeneity of risk attributes among the various industries. Empirical studies have shown that firms from different industry sectors have different risk premia in the bond markets despite receiving identical ratings by the rating agencies (Longstaff and Schwartz, 1995).

As further control variables, we calculate annualized asset volatility and bond betas based on weekly bond prices. We use Barclays Capital Aggregate Bond Index as a benchmark for the estimation of the bond betas. Lastly, we use the classic definition of Altman's (1968) Z-score.

\subsubsection{Bond characteristics}

Additional control variables are included in the models to make the empirical results robust to factors specific to the particular corporate bonds that are used in the analyses. Years to maturity is employed as bonds with longer maturity are expected to have higher default risk. Squared maturity is also included to account for a non-linear effect that the variable might have on credit spreads and bond ratings. The variation of coupon payments and maturities within the sample of corporate bonds leads to differences in duration and convexity, which could also moderate the link between CSP and credit risk. Duration is the standard measure of a bond's interest rate risk and convexity is a measure of the curvature characterizing a bond's price-yield relation and it is a desirable property for bond investors. Both are therefore utilized. The nominal amount issued for each bond represents economies of scale in underwriting that could make the variable inversely related to bond spreads and positively linked with credit ratings. Amount issued could also be thought of as a proxy for bond liquidity (a distinct concept from firm liquidity). Lastly, whenever the log of the spread is used as the regressand, a dummy variable for each of the scores of the ordinal bond rating scale is incorporated in the models. By the construction of the scale, a higher rating should be 
associated with lower credit risk if the opinion of the rating agency is priced in the bond markets. We use this series of dummy variables instead of the scale itself because its ordinal nature is incompatible with the linearity of the panel regression models we apply and thus the values of the slope coefficients would be devoid of meaning. ${ }^{7}$ It could be argued that the rating agencies assess the creditworthiness of bond issues by looking at, among other things, the factors that are explicitly incorporated in this study as control variables, and so the additional inclusion of the rating score dummy variables is unnecessary. However, it has been shown by Sufi (2009) that investors are more reluctant to lend to an issuer who has no rating at all. In other words, there is inherent value in a firm and its bonds being rated by an agency and that is why bond ratings have to be explicitly incorporated in this study in addition to all the other variables. For the sake of parsimony, we do not report the estimates of the slope coefficients of the set of control variables employed in the tables of results.

\subsection{Sample construction}

As has been discussed, information on the corporate social responsibility and irresponsibility of firms is given by the KLD STATS database. We start our sampling by making use of the entire universe of firms covered by KLD in the period from 1991 to 2008. This includes all firms listed in the S\&P 500 Composite Index and in the Domini 400 Social Index. In addition, since 2001, KLD has expanded its coverage universe to incorporate the largest 1,000 U.S. companies in market value (the Russell 1000 index), an expansion that advanced further in 2003 with the inclusion of the 3000 largest U.S. firms (the Russell 3000 index).

We then use Thomson Reuters DataStream to gather the necessary financial information on all the corporate bonds that were issued by the firms included in the sample and were traded in organized bond markets at some point in the 1991-2008 period as well as on the bond issuers themselves. We exclude banks and financial institutions from the sample given that each of them

\footnotetext{
${ }^{7}$ For example, a bond issue with a credit score of two is not expected to have half the credit risk of a bond with a credit score of one.
} 
issues several hundreds of bonds and their inclusion would dominate the sample, thus significantly decreasing its cross-industrial variability. Next, we exclude all floating rate notes, index-linked bonds, convertible bonds, exchangeable bonds, hybrids, preferred bonds, perpetual bonds, private placements, sinking fund provisions, bonds with embedded options or warrants, and bonds with any other nonstandard characteristic. We also exclude all bonds with an issuance volume less than $\$ 100$ million to avoid illiquidity problems.

As highlighted in Section 3.2, we require annual bond yield data to match the frequency of observation of the CSP variables. To achieve this, we take the monthly credit spreads and average them within the year, as described above. Again, to reduce the incidence of unrepresentative yields due to illiquidity effects, we eliminate for a particular year any bonds where there are any trading gaps in trading of more than ten days. Lastly, we do not include government sponsored enterprises (GSEs) in our analysis, as their bonds essentially tend to be considered sovereign rather than corporate assets.

Following this elimination process, we match the CSP data with the relevant financial data on a year by year basis, and after accounting for all of the missing information, we are left with a sample that comprises of a total of 3,240 bonds issued by 742 different firms, spanning 17 different supersectors and traded at some point within the period 1993 to $2008 .^{8}$

\subsection{Model specification}

As has been discussed in the previous subsections of the study, the general forms of the models that are estimated are:

$\log \left(\operatorname{Spread}_{i, t}\right)=f\left(\operatorname{CSP}_{i, t-1}\right.$, firmcharacteristics $_{i, t-1}$, bond characteristics $\left._{i, t-1}\right)$

\footnotetext{
${ }^{8}$ There are no usable observations in 1991 or 1992 due to the unavailability of at least one of the required financial variables. Due to the missing observations for the control variables associated with risk that were added to the analysis, our final sample size is comprized of 7,794 bond-year observations for Tables 4 through 6 .
} 
RScore $_{i, t}=f\left(\right.$ CSP $_{i, t-1}$, firm characteristics $_{i, t-1}$, bond characteristics $\left._{i, t-1}\right)$

Speculative $_{i, t}=f\left(C S P_{i, t-1}\right.$, firmcharacteristics $_{i, t-1}$, bond $_{\text {characteristics }}$ irt-1 $\left._{1}\right)$

where $R S_{\text {core }}, t$ is the bond rating score associated with bond $i$ in year $t$ and Speculative $e_{i, t}$ is a dummy variable equal to one when the bond is of speculative grade and zero when it is of investment grade. CSP measures alternate between the set of individual components (strengths and concerns for all five qualitative business issues of interest) and the aggregate strengths and concerns approach. The firm characteristics and bond characteristics used have already been described. Firm characteristics are the same across all models. The same is true for all bond characteristics except for bond rating scores, which are not used in equations (2) and (3).

Consistent with previous work on the empirical link between CSP and CFP (Hillman and Keim, 2001; Nelling and Webb, 2009; Waddock and Graves, 1997), the independent variables are lagged in all models. This is done for several reasons. Firstly, the primary scope of this study is the examination of the causal relation between CSP and credit risk where CSP is the cause and subsequent levels of credit spreads and bond ratings are the effect. Furthermore, lagging the CSP measures and control variables helps this study escape the potential endogeneity problems and simultaneity bias that can arise due to a contemporaneous bidirectional causality existing between CSP and credit risk. Also, the common practice on the part of KLD is actually to assemble the various social/environmental corporate data at the end of each calendar year, and compile them into spreadsheets at the beginning of the next year. So lagging the CSP variables helps to ensure that the social ratings for each firm were public knowledge at time $t$ and had already started to become incorporated in the markets in the form of informative prices (Godfrey, Merrill, and Hansen, 2009). Thus, when we use CSP measures and financial control variables from the end of 
year $t-1$, we start collecting bond yield data from the fourth week of year $t$ and use bond ratings reported in year $t^{9}$

\subsection{Panel data econometrics}

We use two-way clustering (by both cross-sections and time) to adjust for residuals that are correlated both across bonds and time and to estimate robust standard errors that will lead to valid inferences. This is analogous to the fixed effects approach that is often applied. Clustering in both dimensions is reasonable given that in this multivariate regression, some regressors vary mainly by bond while others vary over time. The use of multiple bonds per firm that are concurrently traded makes it highly probable that both types of dependences arise. As Thompson (2011) notes, twoway clustering reduces estimation bias in such instances. Furthermore, the inclusion of completely time invariant variables (amount of bond issuance, supersector dummy variables) actually makes two-way clustering preferable to fixed effects as in the case of the latter method of estimation, these variables would be implicitly captured by the intercept and could not be directly incorporated into the model specified. Thus, we apply two-dimensional clustering in the panel regressions following the method suggested by Cameron, Gelbach, and Miller (2006) and Thompson (2011). The ordered probit models on bond rating scores and the binary models on the speculative grade dummy are estimated using random effects following Frechette (2001).

\section{Results}

\subsection{Descriptive statistics}

\footnotetext{
${ }^{9}$ In order to further consider potential endogeneity, we test for reverse causality from CSP to yield spreads by regressing the measures of aggregate strengths and aggregate concerns on lagged values of yield spreads and bond ratings along with the usual set of control variables. The results are not presented for brevity but show that the coefficients of the lagged spread and bond ratings variables are statistically insignificant, which indicates that changes in these variables do not seem to cause changes in CSP (while the reverse appears to be true according to our main analyses). We therefore conclude that there is uni-directional causality from CSP to spreads and that endogeneity is not an issue.
} 
Table 1 contains the essential descriptive statistics (mean values, standard deviations, minimum and maximum values) for the key independent, dependent, and control variables (excluding the various industry dummy variables). Looking at the CSP measures, we can see that their mean values are very low due to the absence of many of the indicators from which each individual component has been constructed. They are characterized by a significant degree of variability, however, which is depicted in their standard deviation values that are of significant size, especially when the relevant values of the CSP measures themselves are taken into consideration. All of them have minimum values equal to zero but only in two cases (diversity concerns and product safety and quality concerns) are there instances of firm-year observations that have scores equal to unity (an unsurprising observation given that in order for a firm to have a score of one in any CSP measure during a given year, all the relevant indicators have to be present).

\section{[Insert Table 1 here]}

Corporate credit spreads have a mean value of approximately $2.91 \%$ and are also characterized by a great degree of variability as their standard deviation is equal to $4.12 \%$ with a minimum value of merely $0.014 \%$ (for AAA rated bonds) and a staggering maximum of $125.8 \%$ (for D or CCC rated bonds). The bond rating score statistics are in accordance with the credit spreads. The sample covers the entire spectrum of rating scores from the lowest possible score of one up to the highest of eight. The average bond-year observation has a score close to five, representing the lowest tier of investment grade bonds (from $\mathrm{BBB}-$ to $\mathrm{BBB}+$ ). The standard deviation of the rating scores is approximately equal to 1.12. All of the accounting-based ratios (as well as the yield spreads) are winsorized at the $1 \%$ level in the empirical analyses that are conducted so that outliers do not significantly affect the model estimates.

It is worth examining the variability of the credit spreads and bond rating scores across the various supersectors, which is depicted in Table 2. The Food and beverage, Industrial goods, and Healthcare sectors have the lowest mean spread values $(1.71 \%, 2.35 \%$, and $2.36 \%$ respectively), while the Automobiles and parts, and Telecommunications sectors have the highest $(6.25 \%$ and 
$5.36 \%$ ), although the Automobiles and parts value may not be representative of the credit risk of the sector given the small numbers of observations available. The picture is similar when looking at bond rating scores. Food and beverage, Industrial goods, and Healthcare along with Insurance are the only supersectors with an average rating score greater than five. At the other end of the spectrum, Telecommunications is the only supersector with an average rating score less than four.

\section{[Insert Table 2 here]}

Table 3 presents summary statistics (means, standard deviations, and numbers of observations) for the yield spreads split by CSP score. So Panel A shows that firms with no aggregate strengths have a yield spread that is a statistically significant 90 basis points higher than one with strengths in at least one CSP dimension, which is in line with our hypotheses. However, when we split the sample in terms of concerns in any CSP dimension, we can see that firms exhibiting any form of irresponsible behavior (concerns on at least one dimension) have a spread on average around 50 basis points (and significant at the 1\% level) lower than firms with no concerns along any dimensions. Panel $\mathrm{C}$ of Table 3 examines a simple measure that combines strengths and concerns (by subtracting the latter from the former), with the sample of bonds then being split at the median value of this variable. It is clear here that there is no statistically or economically meaningful difference between the average credit spreads of these two groups. Altogether, the inconclusive findings in Panel C and the counterintuitive result in Panel B serve to illustrate the need for a fuller, multivariate analysis that allows for firm and bond characteristics when investigating the effect of CSP. For example, if it were the case that on average firms with concerns had higher credit ratings, this effect could swamp the effect of CSP.

[Insert Table 3 here]

\subsection{The effect of CSP on credit spreads and bond ratings}

Tables 4 and 5 contain the key results of the empirical analysis. In particular, Table 4 depicts the effects of CSP on the credit spread of corporate bonds. The effect of the individual dimensions 
of CSP as well as their aggregate effect (separate for social and environmental strengths and concerns) is investigated in different models. The estimated coefficients are reported with the respective $p$-values in parentheses. Adjusted R-squared is also reported as a goodness-of-fit measure for every model.

\section{[Insert Table 4 here]}

According to the estimates of the individual CSP dimensions modeled, it appears that community and product safety and quality strengths are significantly negatively related to bond spreads, as are diversity concerns. Employment and community-related concerns on the other hand are shown to be positively linked with the cost of corporate debt. Although the sign and statistical significance of the estimates provide straightforward indications as to the qualitative nature of the relation between CSP and credit spreads, the economic significance of the results is not equally obvious. Because the dependent variable has been log transformed to account for its positive skewness (as it is non-negative by definition), the interpretation is not the same as it is for the slope coefficients of standard linear regressions. When the independent variable of interest changes by unity and all other independent variables remain constant, the percentage change of the dependent variable is equal to the exponent of the calculated coefficient minus one.

So the results show that if a firm completely changes its social posture in terms of its beneficial practices towards local community residents (going from a state where there were no indications in this respect to one where all of the indicators comprising community strengths are now present), it can decrease its corporate spread by $35.6 \%{ }^{10}$ from its previous level so that, for example, a corporate spread of 200 basis points would be decreased to 129. Similarly, a unit increase in product safety and quality strengths can lead to an economically and statistically significant decrease in its cost of debt by approximately $25.7 \%$. On the other hand, the impact that employee dissatisfaction has on debt financing can be detrimental for a corporation since an

${ }^{10}$ Equal to $\exp (-0.4399)-1$. 
increase in employee concerns can lead to a maximum increase of the credit spread by $80.4 \%$ from its previous level. The only aspect of the results that goes against hypothesis 1 comes from the diversity concerns component. It appears that an increase in this type of corporate social controversy actually reduces a firm's cost of debt. However, this is the least economically important result as the related reduction is only $18.2 \%$. The multidimensional CSP measures also support hypothesis 1 as the aggregate strengths coefficient is significantly negatively linked to the dependent variable and aggregate concerns are positively related to spreads. The high-level conclusion that can be drawn is that overall, corporate social responsibility is inversely related to corporate bond spreads while corporate social irresponsibility is positively associated with spreads.

Perhaps the reported estimates look surprisingly high to the reader at first glance. However, putting them into context reveals more about their true magnitude. First of all, by construction, the various measures of corporate social responsibility and irresponsibility used in this study have a minimum value of zero and a maximum value of one (taking various discrete values in between those, depending on how many indicators comprise its component of strengths or concerns). So a change of one unit only happens when a firm goes from having no indications of particular societal/environmental strengths or concerns to displaying all of them. This is a drastic change in a firm's perspective, practices, activities, policies, and even goals, making it time-consuming and possibly very costly. So it is extremely unlikely to empirically observe such a U-turn occurring from one year to the next for a given firm. Secondly, we have tried to emphasize that these figures represent credit spread changes compared to the current level of the bond's spread. So even a unit increase in community strengths for a firm that has issued an AA-rated bond (which has a spread of about $1 \%$ on average in our sample) will be expected to result in the bond's spread being reduced by approximately 35 basis points $(0.43 \times 0.96 \%)$. For a BBB-rated bond, the same change in community strengths should lead to a decrease in its spread of about $1 \%$.

The overall plausibility and goodness of fit of the models are also reinforced by the regression estimates of the control variables (not reported in the table) and the adjusted $\mathrm{R}$-squares. 
Maturity, duration, convexity, and asset volatility are the control variables that are statistically significant and they all have the expected signs in relation to credit spreads (positive for maturity and duration and negative for the others). Bonds issued by more profitable firms with lower maturity and more convex yield curves are associated with lower credit spreads. The negative but algebraically small coefficient for squared maturity, combined with that of the positive estimate for maturity, seems to tell a story consistent with that of a corporate spread curve that is generally increasing in maturity but slightly inverts towards its right end. The only result that is not really intuitive is the positive relation depicted between the firm liquidity measure (current ratio) and credit spreads. However, given that this ratio is really important only for low maturity bonds and that the value of the estimate is low (if the current ratio goes from $0 \%$ to $100 \%$, then the bond spread is expected to increase by approximately 1.05 times), this does not diminish the validity of the model. Adjusted R-squares are around $60 \%$, both in the case of the individual dimensions and for the aggregate CSP metrics.

Table 5 contains the parameter estimates for the econometric models concerning the relation between CSP and credit ratings. The signs of the estimated coefficients and the relevant p-values should provide clear suggestions about the relation between CSP and credit ratings. It appears that there is a strong positive link between the community, employment, environment, and product safety and quality measures of corporate social responsibility and the credit quality of bond issues. At the other end of the spectrum, there is a robust negative relation between the employee controversies that a firm is involved with and its fixed income creditworthiness. There are also hints that community concerns are associated with lower credit ratings and diversity concerns are related to a higher probability of bonds being of investment grade (reinforcing the results coming from the corporate spread regressions), but both of the respective coefficients are less statistically significant than those discussed above, and they are not qualitatively robust across the two different models. The aggregate strengths and aggregate concerns measures of CSP also 
confirm the general picture that is formed, with the former being strongly positively and the latter significantly negatively related to credit quality.

\section{[Insert Table 5 here]}

We employ McFadden's pseudo R-squared as a goodness-of-fit measure for these models. The models where the speculative dummy variable is the regressand have high pseudo $R$-squared values (of the order of $35 \%$ ). On the other hand, for the models concerning the bond rating categories, these statistics fall to about $18 \%$. S\&P use an extensive array of quantitative and qualitative factors to assign credit ratings to specific firms and financial assets. This includes variables and issues relevant to country risk, industry characteristics, company position, marketing, technology utilized, cost efficiency, strategic and operational management competence, capital structure, corporate governance, liquidity, diversification factors, and organizational and corporate culture to name a few. ${ }^{11}$ So it is not surprising that the overall explanatory power of the set of independent variables used in this study is limited in this respect.

The empirical results presented so far can be compared, at least in part, with those of only three other studies: the papers of Ge and Liu (2012), Bauer and Hann (2010) and Menz (2010). As has been already mentioned, the results of the analyses conducted by Ge and Liu (2012) suggest that firms disclosing good CSP are associated with lower bond spreads compared with nondisclosure firms. However, the authors do not find that firms disclosing poor CSP are penalized in the U.S. primary bond market compared with firms that do not disclose their CSP. It is clear that the focal point of Ge and Liu (2012) is the financial effects of CSP disclosure in the primary bond market whereas our study looks into the financial impacts of social responsibility and irresponsibility in the primary and secondary bond markets for firms that already disclose their social performance. Therefore, the two studies investigate related yet distinct issues.

\footnotetext{
${ }^{11}$ For an in-depth assessment of the corporate ratings criteria applied by S\&P, the interested reader is directed to: http://www2.standardandpoor.com/spf//pdf/fixedincome/corporateratings 052007.pdf
} 
Bauer and Hann (2010) find a significant negative relation between environmental strengths and corporate bond spreads and a positive link between environmental concerns and the cost of debt (vice versa for credit quality). On the other hand, the overall association between CSP and yield spreads within the context of corporate bonds of European firms is shown to be insignificant by Menz (2010), while both aggregate strengths and aggregate concerns are shown to be material in the determination of U.S. firms' bond spreads in this study. This could be interpreted as an indication that the European bond markets are lagging the American one with regard to the incorporation of CSP in bond valuation. It should also be noted that the Sustainable Asset Management data set that Menz uses incorporates both economic and social criteria in the assessment of firms and does not discriminate between positive and negative corporate social actions.

\subsection{Investment horizon and the link between CSP and credit spreads}

To further extend our understanding of the relation between CSP and yield spreads, we consider how this link varies according to bond maturity, which will be used as a proxy for investment horizon (thus implicitly assuming that "buy and hold" strategies are implemented by investors). Prior literature within the CSP-CFP research field has argued that the financial benefits of CSP generally accrue in the long run (Hillman and Keim, 2001) and that long-term institutional investors show an appetite for higher CSP performance in the firms that they invest in (Cox, Brammer, and Millington, 2004; Graves and Waddock, 1994). According to the results of the regressions that are contained in Table 6, this view seems to be supported. For the sake of parsimony and in an effort to have a more holistic view of such a phenomenon, we focus on the variation of the financial effect of aggregate CSP. Aggregate concerns have an increasing effect on corporate spreads across all maturities (statistically significant in three out of four subsamples) while for aggregate strengths it is only in the case of corporate bonds with maturities of 20 years or more that the relevant estimated slope coefficient is negatively and significantly related to the cost of corporate debt, signifying that this variable is more strongly connected within a long-term 
investment mindset. So it appears that SRI practitioners also believe in the arguments suggesting that the economic fruits of the consistent, strategic applications of socially responsible principles can be reaped for the firm (and its stakeholders) primarily in the long run. This analysis also stands as a robustness check for the core results of this study and is generally reassuring as the signs of the coefficients of interest remain stable across the majority of the spectrum of bond maturities (negative for social strengths and positive for controversies) and are consistent with the hypothesized links between CSP and credit spreads.

\section{[Insert Table 6 here]}

\subsection{Additional analysis}

In this subsection, we conduct supplemental analysis to reinforce the findings coming from the main part of this study. ${ }^{12}$ Firstly, it would be interesting to split our sample in yet another way to gain further insight concerning the variability of the CSP-spread association according to the rating category to which the bond issues belongs. Specifically, we run regressions for the investment grade bonds and speculative grade bonds separately. Once more, we only use the aggregate CSP measures as we are focusing on additional high-level inferences that can be drawn. The main conclusion from this analysis is that CSP is especially important in the cases of highly rated bonds $(\mathrm{A}+$ to $\mathrm{A}-)$ or very low-rated bonds (CCC+ or lower) where the relation between corporate social activities/practices and the cost of debt is verified in a significant way. Clearly, due to the very high yields of the low-rated bonds, it is the issuers of these assets that can benefit the most, in absolute terms, from the significant reductions in the cost of debt that can materialize mainly through proactive involvement in socially responsible practices.

Secondly, it could be argued that different dimensions of CSP are especially relevant to specific industries where the nature of their business is such that firms are susceptible to increased scrutiny by interested stakeholders and the mass media. If this is true, then the conclusions

\footnotetext{
${ }^{12}$ These empirical results are not reported due to space restrictions but are available from the first author.
} 
concerning the financial effects of disaggregated CSP coming from the analysis conducted on the complete longitudinal sample may not hold in their entirety in that they could arise from industryspecific factors. We make use of the Industry Classification Benchmark (ICB) taxonomy at its second level of analysis (i.e., supersectors), categorize firms according to the exposure of each to alleged stakeholder scrutiny according to the industry in which it operates and repeat the investigation relating to corporate spreads and bond ratings for each subsample of bond-year observations. Similar to the respective results of Bauer and Hann (2010), it appears that no particular differentiation in the strength of the relation between CSP and the cost of debt when categorizing firms according to their industry is detected. In fact the results corroborate the principal findings of the main part of the analysis, as community strengths and product safety and quality strengths are negatively related to spreads, and employee concerns are positively related to spreads across most subsamples.

Thirdly, after calculating Pearson product-moment correlation coefficients for the financial variables of interest, it appears that they are not high enough to warrant concern about the induction of multicollinearity in the regression analyses that have been performed with the exception of the maturity-duration-convexity triplet of variables. Because of the unique economic intuition behind each of these concepts, we elect to use all three of them in our main model specifications and then iteratively drop two of them each time to check the robustness of the results. Indeed, all results remain fundamentally unchanged in terms of the signs, sizes, and statistical significances of the slope coefficients of the key independent variables.

Lastly, because we include multiple bonds per firm in our sample with some of them being traded concurrently, there exists a theoretical possibility that the CSP effect of those firms that issue many bonds dominate those of firms that issue few or one bond, and thus the results of this study cannot be reasonably generalized. To account for this potential limitation, we repeat the core part of the analysis regarding the impact of CSP on the corporate cost of debt, bond ratings, and credit quality using only the single, most liquid bond per firm traded in a given year. The proxy we 
use for bond liquidity is the nominal amount issued. The final data set comprises 3,826 bond-year (or firm-year, it makes no difference in this case) observations. The respective results are very similar to those presented earlier from the regression of the entire sample. The only material difference is that although the aggregate strengths and aggregate concerns variables remain, respectively, negatively and positively connected to spreads, the first connection is statistically insignificant. However, the same variables are significantly related to corporate ratings in a fashion consistent with hypotheses 1 and 2.

\section{Conclusions}

This study is the first to look into the differential impact that various dimensions of corporate social performance have on the pricing of corporate debt as well as the assessment of the credit quality of specific bond issues. The analysis, based on an extensive data set comprising more than 3,000 bonds issued by 742 firms operating in 17 different industries, suggests that support for local communities, higher levels of marketed product safety and quality characteristics, and avoidance of controversies regarding the firm's workforce, can materially reduce the risk premia associated with corporate bonds and thus decrease the cost of corporate debt. Diversity concerns are shown to be negatively related to credit spreads but the effect is less economically significant. These findings appear to be fairly robust across sectors, irrespective of the systematic variation of the operational risks relevant to each of them.

Aggregate CSP metrics are also employed and the results clearly demonstrate that, overall, good performance is rewarded and corporate social/environmental transgressions are penalized through lower and higher corporate bond yield spreads respectively. The same conclusions can be drawn when focusing on either the bond rating assigned to a specific debt issue or the probability of it being considered to be of speculative grade. The results of these analyses are even stronger 
than those coming from the regressions of CSP on credit spreads. It appears that higher levels of CSP can lead to improved credit quality and lower perceived credit risk.

Additional novel contributions arise from the significant efforts that are made to uncover the finer characteristics connecting corporate social performance and bond valuation. It is revealed that bond market participants who apply socially responsible investing principles tend to adhere to the academic consensus suggesting that the financial benefits produced from CSP accrue mainly in the long run as the link between CSP and yield spreads is more significantly negative for longer maturity bonds. Lastly, a look at the variability of the CSP-spread association across credit rating categories provides some indications that suggest that this association is stronger for the highest and lowest rated bonds.

The findings of the study could usefully inform both managerial and investor practices. Firm managers should be aware of the effect that their company's social posture has on the cost of debt financing and the credit quality of its bond issues. Applying efficient, strategic management of the relationships between the corporation and specific stakeholder groups can help in drawing cheaper funds from the fixed-income markets. Proactive application of socially responsible principles can also help avoid instances where a significant controversy concerning firm activities impacting the wider society or the environment lead to overwhelming liquidity squeezes and possible viability issues, as in the case of BP and the Gulf of Mexico oil spill incident. Fixed-income investors should note the relation that CSP is found to have with corporate spreads and bond ratings, and how bond maturity interferes in these links, when assessing the riskiness of the issues they consider investing in. Future research could focus on examining the relation in different bond markets or looking at the portfolio-level equivalent of this analysis and specifying which types of screens (positive or negative and for which CSP dimensions) produce the most successful investment strategies in fixed-income funds. 


\section{References}

Altman, Edward I., 1968. Financial ratios, discriminant analysis and the prediction of corporate bankruptcy, Journal of Finance 23(4), 589-609.

Ashbaugh-Skaife, Hollis, Daniel W. Collins, and Ryan LaFond, 2006. The effects of corporate governance on firms' credit ratings, Journal of Accounting and Economics 42(1-2), 203-243.

Aupperle, Kenneth E. and Deane Van Pham, 1989. An expanded investigation into the relationship of corporate social responsibility and financial performance, Employee Responsibilities and Rights Journal 2(4), 263-274.

Barnett, Michael L., 2007. Stakeholder influence capacity and the variability of financial returns to corporate social responsibility, Academy of Management Review 32(3), 794-816.

Bauer, Rob and Daniel Hann, 2010. Corporate environmental management and credit risk, Working paper, European Centre for Corporate Engagement.

Bauer, Rob, Kees Koedijk, and Roger Otten, 2005. International evidence on ethical mutual fund performance and investment style, Journal of Banking and Finance 29(7), 1751-1767.

Bhojraj, Sanjeev and Partha Sengupta, 2003. Effect of corporate governance on bond ratings and yields: The role of institutional investors and outside directors, Journal of Business 76(3), 455-475.

Brammer, Stephen, Chris Brooks, and Stephen Pavelin, 2006. Corporate social performance and stock returns: UK evidence from disaggregate measures, Financial Management 35(3), 97-116.

Cameron, Colin, Jonah Gelbach, and Douglas L. Miller, 2006. Robust inference with multi-way clustering, National Bureau of Economic Research Cambridge, Mass., U.S.A.

Chan, Ceajer Ka-keung and Nai-Fu Chen, 1991. Structural and return characteristics of small and large firms, Journal of Finance 46, 1467-1484.

Collin-Dufresne, Pierre, Robert S. Goldstein, and J. Spencer Martin, 2001. The determinants of credit spread changes, Journal of Finance 56(6), 2177-2207.

Cox, Paul, Stephen Brammer, and Andrew Millington, 2004. An empirical examination of institutional investor preferences for corporate social performance, Journal of Business Ethics 52(1), $27-43$. 
Edmans, Alex, 2011. Does the stock market fully value intangibles? Employee satisfaction and equity prices, Journal of Financial Economics 101(3), 621-640.

Elton, Edwin J., Martin J. Gruber, Deepak Agrawal, and Christopher Mann, 2001. Explaining the rate spread on corporate bonds, Journal of Finance 56(1), 247-277.

Frechette, Guillaume R., 2001. Update to random-effects ordered probit, Stata May 2001 Technical STB-61, 12.

Frooman, Jeff, Charlene Zietsma, and Brent McKnight, 2008. There is no good reason not to be good. Best Paper Proceedings for the Administrative Science Association of Canada, paper 29-9), 36th Annual meeting, Halifax, Nova Scotia, May 24-27.

Galema, Rients, Auke Plantinga, and Bert Scholtens, 2008. The stocks at stake: Return and risk in socially responsible investment, Journal of Banking and Finance 32(12), 2646-2654.

Ge, Wenxia and Mingzhi Liu, 2012. The impact of corporate social responsibility disclosure and performance on the cost of corporate bonds. CAAA Annual Conference 2012.

Godfrey, Paul, Craig B. Merrill, and Jared M. Hansen, 2009. The relationship between corporate social responsibility and shareholder value: An empirical test of the risk management hypothesis, Strategic Management Journal 30(4), 425-445.

Goss, Allen and Gordon S. Roberts, 2011. The impact of corporate social responsibility on the cost of bank loans, Journal of Banking and Finance 35(7), 1794-1810.

Graves, Samuel B. and Sandra A. Waddock, 1994. Institutional owners and corporate social performance, Academy of Management Journal 37(4), 1034-1046.

Gürkaynak, Refet S., Brian Sack, and Jonathan H. Wright, 2007. The US Treasury yield curve: 1961 to the present, Journal of Monetary Economics 54(8), 2291-2304.

Hillman, Amy J. and Gerald D. Keim, 2001. Shareholder value, stakeholder management, and social issues: What's the bottom line? Strategic Management Journal 22(2), 125-139.

Jensen, Michael C. and William H. Meckling, 1976. Theory of the firm: Managerial behavior, agency costs and ownership structure, Journal of Financial Economics 3(4), 305-360. 
Jones, Thomas M., 1995. Instrumental stakeholder theory: A synthesis of ethics and economics, Academy of Management Review 20(2), 404-437.

Lankoski, Leena, 2009. Differential economic impacts of corporate responsibility issues, Business \& Society 48(2), 206-224.

Lee, Darren D. and Robert W. Faff, 2009. Corporate sustainability performance and idiosyncratic risk: A global perspective, Financial Review 44(2), 213-237.

Longstaff, Francis A. and Eduardo S. Schwartz, 1995. A simple approach to valuing risky fixed and floating rate debt, Journal of Finance 50(3), 789-819.

Luo, Xueming and C. Bhattacharya, 2009. The debate over doing good: Corporate social performance, strategic marketing levers, and firm-idiosyncratic risk, Journal of Marketing 73(6), 198213.

Margolis, Joshua D. and James P. Walsh, 2003. Misery loves companies: Rethinking social initiatives by business, Administrative Science Quarterly 48, 268-305.

Mattingly, James E. and Shawn L. Berman, 2006. Measurement of corporate social action: Discovering taxonomy in the Kinder Lydenburg Domini ratings data, Business \& Society 45(1), 20 46.

McWilliams, Abagail and Donald Siegel, 2000. Corporate social responsibility and financial performance: Correlation or misspecification? Strategic Management Journal 21(5), 603-609.

Menz, Klaus-Michael, 2010. Corporate social responsibility: Is it rewarded by the corporate bond market? A critical note, Journal of Business Ethics 96(1), 117-134.

Merton, Robert C., 1973. Theory of rational option pricing, Bell Journal of Economics and Management Science 4(1), 141-183.

Nelling, Edward and Elizabeth Webb, 2009. Corporate social responsibility and financial performance: The virtuous circle revisited, Review of Quantitative Finance and Accounting 32(2), 197209.

Nelson, Charles R. and Andrew F. Siegel, 1987. Parsimonious modeling of yield curves, Journal of Business 60(4), 473-489. 
Oikonomou, Ioannis, Chris Brooks, and Stephen Pavelin, 2012. The impact of corporate social performance on financial risk and utility: A longitudinal analysis, Financial Management 41(2), 483515.

Renneboog, Luc, Jenke Ter Horst, and Chendi Zhang, 2008a. The price of ethics and stakeholder governance: The performance of socially responsible mutual funds, Journal of Corporate Finance 14(3), 302-322.

Renneboog, Luc, Jenke Ter Horst, and Chendi Zhang, 2008b. Socially responsible investments: Institutional aspects, performance, and investor behavior, Journal of Banking and Finance 32(9), $1723-1742$.

Rubin, Amir, 2008. Political views and corporate decision making: The case of corporate social responsibility, The Financial Review 43, 337-360.

Starks, Laura, 2009. Corporate governance and corporate social responsibility: What do investors care about? What should investors care about? The Financial Review 44, 461-468.

Sufi, Amir, 2009. The real effects of debt certification: Evidence from the introduction of bank loan ratings, Review of Financial Studies 22(4), 1659-1691.

Svensson, Lars E. O., 1994. Estimating and interpreting forward interest rates: Sweden 1992-1994, National Bureau of Economic Research Working Paper No. 4871, Cambridge, Mass., U.S.A.

Thompson, Samuel B., 2011. Simple formulas for standard errors that cluster by both firm and time, Journal of Financial Economics 99(1), 1-10.

Waddock, Sandra A. and Samuel B. Graves, 1997. The corporate social performance-financial performance link, Strategic Management Journal 18(4), 303-319.

Ziebart, David A. and Sara A. Reiter, 1992. Bond ratings, bond yields and financial information, Contemporary Accounting Research 9(1), 252-282. 
Table 1

Summary statistics of key variables

Number of different bond issues: 3, 240; number of different issuing firms: 742;

issuing firms operate in 17 different supersectors and the data set spans across 1992 to 2008.

\begin{tabular}{lcccc}
\hline \multicolumn{1}{c}{ Variable } & Mean & Std. dev. & Min. & Max. \\
\hline Community strengths & 0.049 & 0.117 & 0.000 & 0.750 \\
Diversity strengths & 0.117 & 0.165 & 0.000 & 0.857 \\
Employment strengths & 0.083 & 0.148 & 0.000 & 0.800 \\
Environment strengths & 0.059 & 0.121 & 0.000 & 0.600 \\
Product safety and quality strengths & 0.031 & 0.089 & 0.000 & 0.750 \\
Community concerns & 0.052 & 0.111 & 0.000 & 0.750 \\
Diversity concerns & 0.093 & 0.204 & 0.000 & 1.000 \\
Employment concerns & 0.112 & 0.176 & 0.000 & 0.750 \\
Environment concerns & 0.099 & 0.159 & 0.000 & 0.667 \\
Product safety and quality concerns & 0.158 & 0.222 & 0.000 & 1.000 \\
Aggregate strengths & 0.068 & 0.080 & 0.000 & 0.453 \\
Aggregate concerns & 0.103 & 0.107 & 0.000 & 0.683 \\
Amount issued & 328,515 & 261,326 & 100,000 & $4,000,000$ \\
Convexity & 47.630 & 51.097 & 0.518 & 302.691 \\
Duration & 5.750 & 3.431 & 1.000 & 17.390 \\
Interest coverage ratio & 6.781 & 90.001 & -4285.714 & 2767.380 \\
Leverage & 0.992 & 9.445 & -398.244 & 122.546 \\
Liquidity & 1.338 & 0.953 & 0.000 & 13.260 \\
Maturity & 9.862 & 11.110 & 1.000 & 99.000 \\
Market-to-book value & 2.683 & 12.116 & -233.933 & 625.201 \\
Firm market value & $17,109.5$ & $30,639.9$ & 40.5 & $466,180.0$ \\
Research and development intensity & 0.018 & 0.292 & -0.340 & 22.840 \\
Return on assets & 0.084 & 0.086 & -1.109 & 0.650 \\
Speculative dummy & 0.288 & 0.453 & 0.000 & 1.000 \\
Yield spread & 0.029 & 0.041 & 0.000 & 1.258 \\
Rating score assigned & 4.894 & 1.189 & 1.000 & 8.000 \\
\hline & & & & \\
& & 0.000 &
\end{tabular}


Table 2

Mean spread and rating score by supersector

This table presents the number of observations, the average credit spread (in percentage points per year), and the average credit rating score for each supersector classification.

\begin{tabular}{lccc}
\hline Supersector & Observations & Mean spread & Mean rating \\
\hline Automobiles and parts & 162 & $6.25 \%$ & 4.38 \\
Basic resources & 426 & $3.17 \%$ & 4.55 \\
Chemicals & 404 & $2.49 \%$ & 4.84 \\
Construction and materials & 218 & $2.75 \%$ & 4.85 \\
Food and beverage & 764 & $1.71 \%$ & 5.54 \\
Healthcare & 858 & $2.36 \%$ & 5.42 \\
Industrial goods & 2,277 & $2.35 \%$ & 5.05 \\
Insurance & 638 & $2.79 \%$ & 5.60 \\
Media & 359 & $3.72 \%$ & 4.35 \\
Oil and gas & 1,247 & $2.59 \%$ & 4.63 \\
Personal and household goods & 936 & $3.06 \%$ & 4.90 \\
Real estate & 737 & $3.60 \%$ & 4.94 \\
Retail & 1,165 & $2.91 \%$ & 4.78 \\
Technology & 408 & $3.57 \%$ & 4.70 \\
Telecommunications & 412 & $5.36 \%$ & 3.83 \\
Travel and leisure & 518 & $3.85 \%$ & 4.25 \\
Utilities & 904 & $2.87 \%$ & 4.86 \\
\hline
\end{tabular}


Table 3

Mean yield spreads and two-sample $t$-tests comparing the difference in spreads according to CSP

This table presents the means and standard deviations of the yield spreads for subsamples split according to their CSP, together with $t$-ratios for the differences between the averages for the two categories in each case.

\begin{tabular}{|c|c|c|}
\hline \multicolumn{3}{|c|}{ Panel A: Aggregate strengths } \\
\hline & Observations & Mean \\
\hline & & (Standard deviation) \\
\hline \multirow[t]{2}{*}{ No strengths } & 4,474 & 3.486 \\
\hline & & $(4.296)$ \\
\hline \multirow[t]{2}{*}{ Strengths } & 7,959 & 2.584 \\
\hline & & $(3.984)$ \\
\hline \multirow[t]{4}{*}{$t$-ratio of difference } & & $11.781^{* * *}$ \\
\hline & ggregate conc & ns \\
\hline & Observations & Mean \\
\hline & & (Standard deviation) \\
\hline \multirow[t]{2}{*}{ No concerns } & 3,736 & 3.261 \\
\hline & & $(4.045)$ \\
\hline \multirow[t]{2}{*}{ Concerns } & 8,697 & 2.757 \\
\hline & & $(4.146)$ \\
\hline$t$-ratio of difference & & $6.258^{* * *}$ \\
\hline
\end{tabular}

Panel C: Aggregate strengths minus concerns

Observations Mean

(Standard deviation)

Strengths minus concern below median $\quad 6,216$

Strengths minus concerns above median $\quad 6,217 \quad 2.899$

(4.204)

$t$-ratio of difference

0.280

*** denotes statistical significance at the 0.001 level.

**denotes statistical significance at the 0.01 level.

$*$ denotes statistical significance at the 0.05 level. 
Table 4

The effect of CSP on corporate spreads

The table contains estimates of pooled OLS regressions with two-way (time-dimensional and crosssectional) clustered standard errors; the dependent variable is the natural logarithm of the annualized credit spread; $p$-values are in parentheses. All key financial variables are winsorized at the 1\% level. All regressions include a series of control variables described in Section 3.3 (but their regression coefficients are not reported in the table).

\begin{tabular}{|c|c|c|}
\hline Independent variables & $\ln ($ spread $)$ & $\ln ($ spread $)$ \\
\hline \multirow[t]{2}{*}{ Community strengths } & $-0.4399^{* *}$ & \\
\hline & $(0.001)$ & \\
\hline \multirow[t]{2}{*}{ Diversity strengths } & 0.1253 & \\
\hline & $(0.177)$ & \\
\hline \multirow[t]{2}{*}{ Employment strengths } & 0.1369 & \\
\hline & $(0.123)$ & \\
\hline \multirow[t]{2}{*}{ Environment strengths } & 0.2634 & \\
\hline & $(0.164)$ & \\
\hline \multirow[t]{2}{*}{ Product safety and quality strengths } & $-0.2973^{* *}$ & \\
\hline & $(0.008)$ & \\
\hline \multirow[t]{2}{*}{ Community concerns } & $0.2526^{*}$ & \\
\hline & $(0.016)$ & \\
\hline \multirow[t]{2}{*}{ Diversity concerns } & $-0.2015^{* *}$ & \\
\hline & $(0.003)$ & \\
\hline \multirow[t]{2}{*}{ Employment concerns } & $0.5901^{* * *}$ & \\
\hline & $(0.000)$ & \\
\hline \multirow[t]{2}{*}{ Environment concerns } & 0.1159 & \\
\hline & $(0.138)$ & \\
\hline \multirow[t]{2}{*}{ Product safety and quality concerns } & -0.0193 & \\
\hline & $(0.760)$ & \\
\hline \multirow[t]{2}{*}{ Aggregate strengths } & & $-0.0608^{*}$ \\
\hline & & $(0.039)$ \\
\hline \multirow[t]{2}{*}{ Aggregate concerns } & & $0.6512^{* * *}$ \\
\hline & & $(0.000)$ \\
\hline Firm characteristics & Yes & Yes \\
\hline Bond characteristics & Yes & Yes \\
\hline Supersector fixed effects & Yes & Yes \\
\hline Adjusted $R^{2}$ & $61.55 \%$ & $59.82 \%$ \\
\hline Number of observations & 7,794 & 7,794 \\
\hline
\end{tabular}

$*$ denotes $p<0.05$, ** denotes $p<0.01$, *** denotes $p<0.001$. 
Table 5

\section{Effect of CSP on credit ratings}

The table contains estimates of panel-ordered probit using random effects with robust standard errors; $p$-values are in parentheses. All key financial variables are winsorized at the 1\% level. All regressions include a series of control variables described in the text (but their regression coefficients are not reported in the table).

\begin{tabular}{lllll}
\hline Independent variables & Speculative-grade quality & Speculative-grade quality & Bond rating & Bond rating
\end{tabular}

\begin{tabular}{lcr}
\hline Community strengths & $-4.2047^{* * *}$ & 0.1838 \\
Diversity strengths & $(0.000)$ & $(0.494)$ \\
& -0.5260 & 0.4133 \\
Employment strengths & $(0.465)$ & $(0.082)$ \\
& $-2.8271^{* * *}$ & $2.6321^{* * *}$ \\
Environment strengths & $(0.000)$ & $(0.000)$ \\
& -0.0930 & $1.5108^{* * *}$ \\
Product safety \& quality strengths & $(0.890)$ & $(0.000)$ \\
& $-4.3288^{* *}$ & $0.9553^{*}$ \\
Community concerns & $(0.005)$ & $(0.010)$ \\
& -0.9479 & $-0.5567^{*}$ \\
Diversity concerns & $(0.193)$ & $(0.026)$ \\
& $-0.9962^{*}$ & -0.1028 \\
Employment concerns & $(0.036)$ & $(0.525)$ \\
Environment concerns & $2.4561^{* * *}$ & $-0.7406^{* * *}$ \\
Product safety \& quality concerns & $(0.000)$ & $(0.000)$ \\
& 0.4291 & 0.4239 \\
& $(0.542)$ & $(0.058)$ \\
& 0.1266 & -0.2607 \\
& $(0.782)$ & $(0.084)$
\end{tabular}

Aggregate strengths

$-8.8997^{* * *}$

$7.5770^{* * *}$

$(0.000)$

Aggregate concerns

$2.0580^{*}$

$-2.0381^{* * *}$

(0.019)

$(0.000)$

Firm characteristics

Yes

Yes

Yes

Bond characteristics

Yes

Yes

Yes

Supersector fixed effects

Yes

Yes

Yes

Yes

Pseudo- $R^{2}$

$36.26 \%$

$35.56 \%$

$18.60 \%$

$17.70 \%$

Number of observations

7,794

7,794

7,794

7,794

$*$ denotes $p<0.05, * *$ denotes $p<0.01, * * *$ denotes $p<0.001$ 
Table 6

The effect of CSP on corporate spreads with regard to investment horizon

The table contains estimates of pooled OLS regressions with two-way (time-dimensional and cross-sectional) clustered standard errors; the dependent variable is the natural logarithm of the annualized credit spread; $p$ values are in parentheses. All key financial variables are winsorized at the $1 \%$ level. All regressions include a series of control variables described in the text (but their regression coefficients not reported in the table).

\begin{tabular}{lcccc}
\hline Years to maturity: & 5 or less & 5 to 10 & 10 to 20 & more than 20 \\
\hline Independent variables & $\ln ($ spread) & $\ln ($ spread $)$ & $\ln ($ spread $)$ & $\ln ($ spread $)$ \\
\hline Aggregate strengths & -0.1941 & -0.1218 & 0.0422 & $-0.3931^{* *}$ \\
Aggregate concerns & $(0.344)$ & $(0.380)$ & $(0.816)$ & $(0.007)$ \\
& $0.9633^{* *}$ & $0.4698^{*}$ & 0.2003 & $0.4878^{* *}$ \\
Firm characteristics & $(0.002)$ & $(0.017)$ & $(0.139)$ & $(0.005)$ \\
Bond characteristics & Yes & Yes & Yes & Yes \\
Supersector fixed effects & Yes & Yes & Yes & Yes \\
\hline Adjusted $R^{2}$ & Yes & Yes & $73.33 \%$ & $69.93 \%$ \\
Number of observations & $49.13 \%$ & $74.29 \%$ & 7,794 & 7,794 \\
\hline
\end{tabular}

$*$ denotes $p<0.05, * *$ denotes $p<0.01$, *** denotes $p<0.001$ 